\title{
Comparison of Line Probe Assay (LPA) and Mycobacterium Growth Indicator Tubes (MGIT) Assay for Second-line TB Drug Susceptibility Testing
}

\author{
Towifah Fauziah Choerunisa ${ }^{1}$, Leni Lismayanti ${ }^{1}$, Tiene Rostini ${ }^{1}$, Ryan Bayusantika ${ }^{2}$, Ida Parwati ${ }^{1, *}$ \\ ${ }^{1}$ Department of Clinical Pathology, Faculty of Medicine, Universitas Padjadjaran/Dr. Hasan Sadikin General Hospital, Jl. Raya Bandung Sumedang \\ KM 21, Jatinangor 45363, Indonesia \\ ${ }^{2}$ West Java Provincial Laboratory, Jl. Sederhana No.3-5, Bandung 40161, Indonesia. \\ *Corresponding author. E-mail: ida.parwati@unpad.ac.id
}

Received date: Feb 12, 2021; Revised date: Apr 21, 2021; Accepted date: Apr 21, 2021

\section{Abstract}

B ACKGROUND: Tuberculosis (TB) infection is one of the most prominent health issues in the world, including in Indonesia. TB is evolving into multidrug-resistant tuberculosis (MDR-TB) and requiring second-line TB drugs. Mycobacterium growth indicator tube (MGIT) is the gold standard for susceptibility testing of second-line TB drugs. Alternatively, line probe assay (LPA), which detects genes resistant to second-line TB drugs, takes a shorter time to run. This study aims to compare MGIT and LPA's ability to detect TB resistance to second-line TB drugs and observe mutation patterns of genes encoding second-line TB drugs.

METHODS: This was an observational analytic study, using cross-sectional method. The data were acquired from the MDR-TB clinic's medical records at the Dr. Hasan Sadikin Hospital from September to December 2019. LPA and MGIT test were conducted at the Health Laboratory Hall of West Java Province, then tested using KolmogorovSmirnov and chi-square statistic.

RESULTS: From 121 subjects, 113 people were not resistant to the second-line TB drugs, which was examined using both LPA and MGIT (93.4\%), $p=0.991$. Mutations were found in $g y r A$ and $r r s$ gene. There was no significant difference between the proportion of subjects resistant to the second-line of TB drugs tested using LPA and MGIT.

CONCLUSION: LPA is an alternative method to MGIT because it requires a shorter time and reduces the risk of exposure that will improve MDR-TB patients management.

KEYWORDS: line probe assay (LPA), multidrug-resistant $\mathrm{TB}$, mycobacterium growth indicator tube (MGIT), secondline TB drugs

Indones Biomed J. 2021; 13(3): 256-60

\section{Introduction}

Tuberculosis (TB) infection caused by Mycobacterium tuberculosis (MTB) is remains as one of the prominent health issues in Indonesia and in the world. Although TB infection is curable, many TB infections are currently evolving into a multidrug-resistant tuberculosis (MDRTB) and requiring second-line TB drugs to generate an effective treatment.(1) To ensure the absence of resistance to the second-line TB drugs, a susceptibility test must be conducted. The gold standard is to use a conventional (phenotypic) test by utilizing the mycobacterium growth indicator tube (MGIT) to obtain a good result of the second-line TB drugs susceptibility test.(2) However, this method takes approximately 6-10 weeks, starting from the creation of MTB culture until the TB drugs susceptibility test to fluoroquinolone (i.e., levofloxacin and moxifloxacin) and aminoglycoside (i.e., amikacin, kanamycin, and capreomycin).(2,3) Alternatively, there is a rapid molecular 
test by directly examining the sputum samples using the line probe assay (LPA). The alternate method only takes approximately 6 hours. The LPA which is a genotypic test will examine the MTB's gyrA and gyrB genes to detect fluoroquinolones resistance and $r r s$ and eis genes to detect aminoglycosides resistance.(4)

The difference between the LPA and MGIT as a phenotypic test results is in MGIT's inability to detect every gene mutation as resistance. It mainly on account of the silent mutations undetectable in the phenotypic examination. It is a fact that changes in the genetic stage may occur without alteration of every protein.(5) Besides due to silent mutation, the difference of test result may also occur due to the gene mutations in codons/regions outside of the standardized probe in the LPA test. This other type of gene mutation may go undetected as a gene mutation in the MTB infection. However, it is interpreted as a resistance to the second-line TB drugs on the MGIT test.(6) There is not enough study comparing the proportion of secondline TB drugs resistance on LPA and MGIT examinations in Indonesia. This study will compare the proportion of second-line TB drugs resistance on LPA and MGIT tests.

\section{Methods}

This was an observational analytic study which compares the results of two groups of research using cross-sectional method. This study had obtained ethical approval from the Research Ethics Committee of Dr. Hasan Sadikin General Hospital (No. LB.02.01/X.6.5/129/2020).

\section{Subject Recruitment}

The data was obtained from the MDR-TB clinic at the Dr. Hasan Sadikin General Hospital, Bandung, from September to December 2019. The inclusion criteria were the age of MDR-TB patients should be above 18 years, MDR-TB should be diagnosed by GeneXpert at the Dr. Hasan Sadikin Bandung General Hospital, and was not yet treated by the second-line TB drugs.

Subjects who failed the first-line TB drugs had not received any second-line TB drugs; after being diagnosed as resistant to the first-line of TB drugs, they were directly tested using LPA and MGIT at the Health Laboratory Hall of the West Java Province. The comparison of the secondline TB drugs resistance test using the LPA and MGIT was obtained from the West Java Provincial Laboratory within the study period.

\section{MGIT and LPA Methods for Second-Line TB Drugs Susceptibility Test}

Bactec MGIT 960 drug susceptibility test was performed as the gold standard for determining resistance. The following critical concentrations of drugs recommended by WHO for testing of drug-resistant TB using Bactec MGIT 960 DST were used: fluoroquinolone: levofloxacin $1 \mu \mathrm{g} / \mathrm{mL}$, moxifloxacin $1 \mu \mathrm{g} / \mathrm{mL}$ (high dose) and $0.25 \mu \mathrm{g} /$ $\mathrm{mL}$ (low dose); aminoglycoside: amikacin, kanamycin, capreomycin.(7)

LPA test with GenoType MTBDRsl VER 2.0 assay was performed, each strip contains 27 reaction zones with probes for all specific targeted regions. Seven probes for gyrA (A90V, S91P, D94A, D94N/Y, D94G, and D94H) and 2 probes for $\operatorname{gyrB}$ (N538D and E540V) were used to detect fluoroquinolone resistance. Second-line injectable drugs (SLID) resistance was detected by selected rrs (A1401G, C1402T, and G1484T) and eis (C-14T and C-12T) probes. The presence of all wild-type bands and absence of mutation bands indicated susceptibility. The presence of specific mutation bands was considered as defined mutation, and the absence of wild-type bands was considered as undefined mutation. SLID resistance referred to resistance to at least one of the 3 injectable drugs (amikacin, kanamycin, capreomycin).(8)

\section{Statistical Analysis}

The data was tested for normality using KolmogorovSmirnov and further analysed using the chi-square method utilizing Statistical Package for the Social Sciences (SPSS) software, version 24.0 for Windows (IBM Coorporation, Armonk, NY, USA).

\section{Results}

From the medical record of subjects with MDR-TB infection, we included 140 subjects in the study. However, only 121 subjects meet the inclusion criteria. Nineteen subjects were excluded because the result from GeneXpert showed that the MTB were detected to be low and very low (CT value $=22-28$ and $>28$, respectively).

\section{Sample Characteristics}

The subjects' age range was 30-50 years old, with the median of 38 years old. There were 60 male subjects $(49.6 \%)$ and 61 female subjects (50.4\%). There were 99 subjects $(81.8 \%)$ who failed the first-line TB drugs therapy, and 22 subjects 
(18.2\%) entered the second-line TB drugs therapy without previous history of the first-line TB drugs. The characteristic of the study subjects could be seen in Table 1 .

\section{The Comparison between LPA and MGIT on Resistance of Second Line TB Drugs}

The comparison of proportion between the resistance to the second-line TB drugs using the LPA and MGIT test could be found in Table 2. It showed no significant difference in the proportion of resistance against the second-line TB drugs using the LPA and MGIT test, considering that $p=0.991$ $(p \geq 0.05)$. The tests conducted using LPA indicated that there were three subjects with gene mutations who were not resistant to the MGIT test $(2.5 \%)$. Meanwhile, four issues were identified without gene mutations after the LPA test and simultaneously resistant against the MGIT test (3.3\%). Most of the test subjects, 113 people, were non-resistant against both methods (93.4\%), $p=0.991$.

Meanwhile, from the 121 research subjects, there was $1(0.83 \%)$ subject with extensively drug-resistance tuberculosis (XDR-TB). This subject was detected as resistant to the fluoroquinolones and the aminoglycosides within the LPA and MGIT test results. The interpretation of gene mutation in LPA is shown in Table 3.

In this study, 113 subjects were not resistant to the second-line TB drugs through both LPA and MGIT tests, while one subject was accounted as resistant in both tests. On the other hand, three subjects were considered resistant in the LPA test, but not resistant in the MGIT test. On the contrary, four subjects were identified as not resistant in the LPA test yet resistant in the MGIT test.

\section{Discussion}

The LPA test application in diagnosing patients' resistance against TB drugs helps clinicians decide better therapy for the MDR-TB patients since it requires a shorter time. The Ministry of Health of Indonesia issued Technical
Table 1. Study subjects' characteristics.

\begin{tabular}{lc}
\hline \multicolumn{1}{c}{ Variables } & $\begin{array}{c}\text { Value } \\
(\mathbf{n = 1 2 1})\end{array}$ \\
\hline Age (years old), median (range) & $38.0(30-50)$ \\
\hline $\begin{array}{l}\text { Gender, n (\%) } \\
\text { Male }\end{array}$ & $60(49.6)$ \\
Female & $61(50.4)$ \\
\hline Type of therapy, n (\%) & \\
Failed the first line therapy & $99(81.8)$ \\
New patients & $22(18.2)$ \\
\hline
\end{tabular}

Guidelines on the MDR-TB Treatment in 2017. It is stated in the guidelines that patients who are not resistant to fluoroquinolones and aminoglycosides according to the TB drugs sensitivity test either through phenotypic (MGIT) test or rapid molecular test (LPA), shall be eligible for shortterm MDR-TB therapy (9-11 months). Besides, LPA brings a lower risk of exposing MTB to the examination operator during the analytical process since it only examines genetic materials of MTB, compared to the MGIT, which involves exposure to the human serum. $(9,10)$

In this study, the proportion of results in the secondline TB drugs test using the LPA and MGIT method (3.3\% and $4.1 \%$ ) did not show a significant difference. Similar results are stated by a study conducted in South Africa that the proportion of resistance against Fluoroquinolone in LPA and MGIT tests was 17.7\% (16/90) and 10\% (9/90), respectively. Meanwhile, the proportion of resistance against kanamycin in LPA and MGIT tests was $5.5 \%(5 / 90)$ and 3.3\% (3/90), respectively.(11) Other LPA examination in South Africa used the same tool with previous study, namely the LPA Genotype MTBDRsl version 2.0. The study in South Africa used cultures from patients positively infected with MTB, whereas in this study, the author used a sample directly taken from sputum.(12) Interfering factors in the LPA test are the presence of blood, guaifenesin, mupirocin, and pus in the sputum sample.

Table 2. Comparison of proportion in the resistance towards second-line TB drugs in the LPA and MGIT test.

\begin{tabular}{|c|c|c|c|}
\hline \multicolumn{3}{|c|}{$n(\%)(n=121)$} & \multirow[b]{2}{*}{$p$-value } \\
\hline $\begin{array}{c}\text { Resistance in } \\
\text { LPA }\end{array}$ & $\begin{array}{c}\text { Resistance in } \\
\text { MGIT }\end{array}$ & $\begin{array}{c}\text { Resistance in Both } \\
\text { LPA and MGIT }\end{array}$ & \\
\hline $4(3.30 \%)$ & $5(4.10 \%)$ & $1(0.83 \%)$ & 0.991 \\
\hline
\end{tabular}

$p$-value was tested with chi-square to find the comparison of positive resistance between the LPA and MGIT test. 
Table 3. Interpretation of gyrA, gyrB, rrs, and eis mutation gene in LPA examination.

\begin{tabular}{|c|c|c|c|c|c|c|}
\hline \multirow{3}{*}{$\begin{array}{c}\text { Line Probe } \\
\text { Assay (LPA) } \\
\text { Gene }\end{array}$} & \multicolumn{6}{|c|}{ Interpretation in LPA Examination Result } \\
\hline & \multicolumn{2}{|c|}{ Fluoroquinolone } & \multicolumn{3}{|c|}{ Aminoglycoside } & \multirow{2}{*}{ Amount } \\
\hline & Levofloxacin & Moxifloxacin & Amikacin & Kanamycin & Capreomycin & \\
\hline gyrA Mut 1 & Resistance & Resistance low dose & - & - & - & 1 \\
\hline gyrA Mut 2 & Resistance & Resistance low dose & - & - & - & 1 \\
\hline gyrA Mut 3A & Resistance & Resistance low dose & - & - & - & 0 \\
\hline gyrA Mut 3B & Resistance & Resistance high dose & - & - & - & 0 \\
\hline gyrA Mut 3C & Resistance & Resistance high dose & - & - & - & 1 \\
\hline gyrA Mut 3D & Resistance & Resistance high dose & - & - & - & 0 \\
\hline $\operatorname{gyr} B$ Mut 1 & Resistance & Resistance low dose & - & - & - & 0 \\
\hline $\operatorname{gyr} B$ Mut 2 & Resistance & Resistance low dose & - & - & - & 0 \\
\hline rrs MUT 1 & - & - & Resistance & Resistance & Resistance & 2 \\
\hline$r r s$ MUT 2 & - & - & Resistance & Resistance & Resistance & 1 \\
\hline eis MUT 1 & - & - & Resistance & Resistance & Resistance & 0 \\
\hline
\end{tabular}

MTB strains in South Africa are different from Indonesia; South Africa has East-African Indian MTB strain, while West Java has Beijing MTB, a genotype family.(13) A study in Beijing showed that MTB genotype in Indonesian people played a role as one of the risks leading to therapy failure.(14) This notion is supported by another study, which stated that the MTB with multiple drug resistance has a more significant population in Asia than in South Africa.(15) Despite the interfering factors and different samples, there is no significant difference in the study results between the studies conducted in South Africa and Indonesia.

This study showed that $4(3.3 \%)$ patients who were resistant to the second-line TB drugs in the MGIT test have no gene mutation detected in their LPA test. This might occur due to gene mutation outside of the probe codon in the LPA test. As mentioned above, people in West Java mostly have MTB population from the Beijing genotype family, which gyrA gene has quinolone resistance-determining region (QRDR) at codons 74-113.(13,14) The LPA tests in this study were limited to codons $85-97$ as the codons with the most mutation. This factor became the main reason the LPA test results show no resistance against the Fluoroquinolone, whereas the MGIT show resistance against the same substance. The gene mutation went undetected by the probe in the LPA test. However, the protein produced due to the gene mutation itself read as resistance against the secondline drugs in the MGIT test.(6) Different from the gyrA gene, the gyrB gene in the MTB Beijing strain genotype family has a QRDR at codons 500-540. In this study, there were no research subjects with $g y r B$ gene mutation in their
MTB. The $\operatorname{gyr} B$ gene codons examined in this study were codons 497-502, 536-541. A study in Taiwan also stated that the gene mutations in MTB are more often found in gyrA gene than in the gyrB gene.(16)

The $r r s$ and eis are the genes creating $16 \mathrm{~S}$ ribosomal protein codes in MTB. The LPA test detects these genes to examine MTB sensitivity against aminoglycosides. In the Beijing genotype family, these genes have aminoglycoside resistance-determining region (ARDR) at codons 1401, 1402, and 1484. This study conducted the LPA test against the rrs and eis genes at codon A1401g, region 1400, g1484t, and region 1484.(17)

From the research subjects, $3(2.5 \%)$ patients showed gene mutation in the LPA test and no resistance against the second-line TB drugs in the MGIT test. Such a result might be caused by a silent mutation. A silent mutation causes a change in one genetic code; however, it does not change the amino acids coded. Therefore, a silent mutation will not change the protein resulting from the coding process. Another study showed that $99.8 \%$ of genes with "silent mutation" do not cause a change of amino acids during translation.(18) Moreover, it was also found that a silent mutation in the nucleotide arrangement of the $g y r B$ gene in MTB during the formation of isoleucine proteins, namely isoleucine (ATC sequence) to isoleucine (ATT sequence). (19) DNA sequencing (pyrosequencing) can be used to detect silent mutation in specific nucleotides.(20) A study proved that high positivity rates of pyrosequencing to detect drug-resistant TB directly from sputum samples with different grades of smear microscopy as the surrogate of bacterial load.(21) 


\section{Conclusion}

There was no significant difference between patients' possibility of resistance to the second-line TB drugs tested by LPA and MGIT. Clinicians may acquire LPA test results in a matter of hours, while MGIT must be done in weeks. In conclusion, the LPA may serve as a good alternative to the MGIT because it requires a shorter time and reduces the risk of exposure for the examiner in conducting the susceptibility test against the second-line TB drugs for the MDR-TB patients.

\section{Acknowledgements}

The authors thank the employees of Health Laboratory Hall of the West Java Province and MDR-TB team in Dr. Hasan Sadikin General Hospital for their technical support for this research.

\section{Authors Contribution}

IP, TR, and LL were involved in planning and supervised the work, TF performed the measurements, and together with $\mathrm{RB}$ processed the experimental data, performed the analysis, drafted the manuscript and designed the figures. TF performed the calculations and statistical analysis. TF and LL aided in interpreting the results and worked on the manuscript. All authors discussed the results and commented on the manuscript.

\section{References}

1. Floyd K, Anderson L, Baddeley A, Baena IG, Gebreselassie N, Gilpin C, et al. Global Tuberculosis Report. Geneva: WHO; 2018.

2. Lima SSS, Clemente WT, Palaci M, Rosa RV, Antunes CM de F, Serufo JC. Conventional and molecular techniques in the diagnosis of pulmonary tuberculosis: a comparative study. J Bras Pneumol. 2010; 34: 1056-62.

3. Kalokhe AS, Shafiq M, Lee JC, Ray SM, Wang YF, Metchock B, et al. Multidrug-resistant tuberculosis drug susceptibility and molecular diagnostic testing. Am J Med Sci. 2013; 345: 143-8.

4. Hain Lifescience. Genotype MTBDRplus VER 2.0: Molecular Genetic Assay for Identification of the M. tuberculosis Complex and its Resistance to Rifampicin and Isoniazid from Clinical Specimens and Cultivated Samples. Nehren: Hain Lifescience GmbH; 2012.
5. Metchock B. New TB Diagnostic Tools and the Challenges of Interpreting Discordant Results. Atlanta: Souteatern Natl TB Center, CDC; 2012.

6. GLI Line Probe Assays for Drug-resistant Tuberculosis Detection Interpretation and Reporting Guide for Laboratory Staff and Clinicians. [n.p.]: Global Laboratory Iniative; 2018.

7. GLI. Mycobacteriology Laboratory Manual. [n.p.]: Global Laboratory Iniative; 2014.

8. Gardee Y, Dreyer AW, Koornhof HJ, Omar SV, Silva P, Bhyat Z. Evaluation of the genotype MTBDR sl tuberculosis isolates in South Africa. J Clin Microbiol. 2017; 55: 791-800.

9. Nguyen L. Antibiotic resistance mechanisms in M. tuberculosis : an update. Arch Toxicol. 2016; 90: 1585-604.

10. Kemenkes RI. Petunjuk Teknis Pengobatan Pasien TB Resistan Obat dengan Panduan Standar Jangka Pendek di Fasyankes TB Resistan Obat. Jakarta: Kemenkes RI; 2017.

11. Maningi NE, Malinga LA, Antiabong JF, Lekalakala RM, Mbelle NM. Comparison of line probe assay to BACTEC MGIT 960 system for susceptibility testing of first and second-line anti-tuberculosis drugs in a referral laboratory in South Africa. BMC Infect Dis. 2017; 17: $1-8$.

12. Hain-Lifescience. GenoType MTBDRsl VER 2.0 - Instructions for use. IFU-317A-01. Nehren: Hain Lifescience GmbH; 2015.

13. Parwati I, Van Crevel R, Sudiro M, Alisjahbana B, Pakasi T, Kremer $\mathrm{K}$, et al. Mycobacterium tuberculosis population structures differ significantly on two Indonesian islands. J Clin Microbiol. 2008; 46: 3639-45.

14. Parwati I, Alisjahbana B, Apriani L, Soetikno RD, Ottenhoff TH, van der Zanden AGM, et al. Mycobacterium tuberculosis Beijing genotype is an independent risk factor for tuberculosis treatment failure in Indonesia. J Infect Dis. 2010; 201: 553-7.

15. Couvin D, Reynaud Y, Rastogi N. Two tales: Worldwide distribution of Central Asian (CAS) versus ancestral East-African Indian (EAI) lineages of Mycobacterium tuberculosis underlines a remarkable cleavage for phylogeographical, epidemiological and demographical characteristics. PLoS ONE 14(7): e0219706. doi: 10.1371/journal.pone.0219706.

16. Chien J, Chiu W, Chien S, Chiang C, Yu C, Hsueh P. Mutations in gyrA and gyrB among fluoroquinolone- and multidrug- resistant mycobacterium tuberculosis Isolates. Antimicrob Agents Chemother. 2016; 60: 2090-6.

17. Ali A, Hasan R, Jabeen K, Jabeen N, Qadeer E, Hasan Z. Characterization of mutations conferring extensive drug resistance to Mycobacterium tuberculosis isolates in Pakistan. Antimicrob Agents Chemother. 2011; 55: 5654-9.

18. Weber W. Silent Mutation. Oxford: Oxford Univ Press USA; 2008.

19. Cui Z, Wang J, Lu J, Huang X, Hu Z. Association of mutation patterns in gyrA/B genes and ofloxacin resistance levels in Mycobacterium tuberculosis isolates from East China in 2009. BMC Infect Dis. 2011; 11: 78. doi: 10.1186/1471-2334-11-78.

20. Ndjeka N, Richard P, Farley J, Lowensen K, Mlandu N, Nyakinye $\mathrm{K}$, et al. Multidrug-Resistant Tuberculosis National Clinical Management Training. Singapore: Pyrobett; 2017.

21. Syafira SZ, Zavitri NG, Yan S, Sribudiani Y, Lezhava A, Chaidir L. Positivity rate of pyrosequencing to diagnose drug-resistant tuberculosis directly from sputum with different bacterial load. Indones Biomed J. 2020; 12: 313-9. 